REVISTA

de la

C

E

PAL

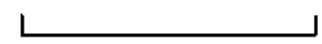

NUMERO 63

DICIEMBRE 1997

SANTIAGO DE chile

OSCAR ALTIMIR

Director

EUGENIO LAHERA

Secretario Técnico

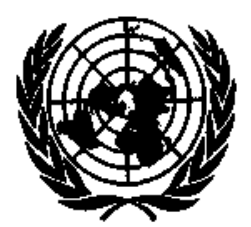

NACIONES UNIDAS 
El papel del sector público en el desarrollo latinoamericano

Ricardo Carciofi

La equidad en el presupuesto público

Juan Martin

Reformas a los sistemas de pensiones, mercado de capitales y ahorro

Andras Uthoff

Institucionalidad pública y políticas ambientales explícitas

e implícitas

Nicolo Gligo

La valoración de recursos naturales y ambientales no basada en el mercado en Centroamérica y el Caribe

Steve Shultz

Un modelo macroeconómico integrado para el Caribe

Lucio Vinhas de Souza

Virajes y derrapajes de la economía venezolana

José Miguel Benavente

¿Cuan no tradicionales son las exportaciones no tradicionales?

La experiencia de siete países de la Cuenca del Caribe

Alberto Gabriele

Apertura comercial y cambio estructural en la industria automotriz brasileña

Ruy de Quadros Carvalho, Sergio Robles Reis de Queiroz,

Flávia Luciane Consoni, loriara Costa y Janaína Pamplona da Costa

Historia evolutiva de una planta metalmecánica chilena

Jorge Katz y Héctor Vera

La importancia de lá producción local y la pequeña empresa para el desarrollo de América Latina

Francisco Alburquerque

Publicaciones recientes de la CEPAL 


\section{Historia evolutiva \\ de una planta \\ metalmecánica chilena}

\author{
Jorge Katz* \\ Héctor Vera** \\ *Asesor Regional en \\ Desarrollo Industrial y \\ Tecnológico de la División \\ de Desarrollo \\ Productivo y Empresarial \\ de la CEPAL \\ ** Consultor de la \\ misma División
}

Los procesos de ajuste y reestructuración de los sectores productivos a un nuevo régimen de incentivos macroeconómicos son lentos, costosos y más imperfectos que lo que la teoría microeconómica convencional lleva a suponer. Los autores exploran aquí el proceso de reestructuración productiva de una firma metalmecánica chilena, y la forma en que ella fue modificando su operatoria a partir de los años setenta, adaptándola a nuevas señales macroeconómicas y mesoeconómicas. Como se sabe, en las últimas dos décadas el régimen de incentivos y el marco regulatorio en el que se desenvuelve la actividad productiva chilena experimentaron una profunda transformación. Gradualmente se fue transitando — con marchas y contramarchas - hacia un modelo de organización más abierto a la competencia externa, más desregulado y con menor participación del sector público en el ámbito estrictamente productivo. En el caso de la firma aquí estudiada, pese al ya extenso período de apertura externa de la economía chilena y a que la firma ha alcanzado un marcado éxito en su reestructuración global, la transición hacia niveles internacionales de productividad es aún incompleta y muestra ámbitos de fragmentación y debilidad. En la primera sección del artículo se presenta el cuadro general del funcionamiento de la economía chilena en que se inscribe la historia de la empresa examinada; en la segunda se describe la evolución de la planta fabril de dicha empresa $y$, finalmente, en la tercera se exploran los vínculos entre lo microeconómico y lo macroeconómico y se plantean algunas reflexiones finales derivadas de esta investigación. 


\section{I}

\section{Introducción}

Los economistas tienden a privilegiar la lectura macroeconómica de la realidad y, por lo tanto, a prestar menos atención a las historias de agentes económicos individuales. En parte ello es así porque la teoría convencional de los precios está construida sobre la base del comportamiento estilizado de un 'agente representativo' dado, que maximiza las ganancias en condiciones de perfecta información. En un marco analítico de esta índole se puede suponer que a la larga las ramas o sectores productivos se ajustan a un nuevo conjunto de señales macroeconómicas, siendo irrelevante el sendero de adaptación de una firma en particular.

Sin embargo, la observación de la realidad nos muestra que los procesos de ajuste y reestructuración de un determinado sector productivo a un nuevo régimen de incentivos son lentos, costoso y más imperfectos que lo que la teoría microeconómica convencional nos llevaría a suponer. En el mercado hay entradas y salidas de firmas, procesos graduales de reorganización fabril, así como cambios en los niveles de integración vertical de las plantas, en la propiedad de las empresas, en el nivel de concentración económica sectorial, a lo largo de un episodio complejo y altamente idiosincrático de mutación estructural. La interdependencia entre lo macro, lo meso y lo micro nos es todavía esencialmente desconocida, pese a que de modo intuitivo percibimos que el proceso de ajuste bien puede acabar condicionando de manera irreversible la estructura y el comportamiento de largo plazo de la rama productiva o economía considerada.

En las últimas dos décadas el régimen de incentivos y el marco regulatorio en el que se desenvolvió la actividad productiva chilena sufrieron una profunda transformación. Gradualmente se fue transitando ha- cia un modelo de organización productiva más abierto a la competencia externa, más desregulado y con menor participación del sector público en el ámbito estrictamente productivo.

Los agentes económicos individuales fueron adaptándose lentamente a estos cambios. Sabemos poco, sin embargo, de la forma en que a nivel microeconómico - o sectorial — se fueron metabolizando estos complejos procesos de mutación estructural.

Desde esta perspectiva, nos ha parecido interesante explorar el proceso de reestructuración productiva de una firma metalmecánica chilena - la Compañía Tecno Industrial (en) - y examinar de qué manera ella fue modificando sus operaciones a lo largo de las últimas tres décadas, para irse adaptando a las nuevas señales macroeconómicas y mesoeconómicas. Por otro lado, también nos ha parecido relevante preguntarnos hasta qué punto la evolución de la CTI refleja lo ocurrido en la industria metalmecánica chilena en su conjunto.

Mostraremos aquí que pese a la ya prolongada apertura externa de la economía chilena, y a la exitosa reestructuración global de la firma estudiada, la transición hacia los niveles tecnológicos internacionales es aún incompleta, y muestra ámbitos de fragmentación y debilidad. Sólo en fecha reciente - al iniciarse las conversaciones sobre el posible ingreso de Chile al Mercosur - la CTI comenzó a percibir que en adelante debería enfrentar una más fuerte competencia de grandes productores mundiales, y que debería tomar muy en cuenta la organización productiva y el ritmo de cambio tecnológico que esta rama de industria exhibe en el mundo desarrollado, si desea preservar su independencia de largo plazo.

\section{II}

\section{El contexto global chileno en el período 1970-1994}

El sector manufacturero chileno pasó por varios períodos de crisis y resurgimiento a lo largo de las tres últi-

'.'..: El presente estudio fue realizado con la colaboración de diversos profesionales de la Compañía Tecno Industrial (CTI) y se publica tras expresa consulta con esta firma, cuya cooperación y acuerdo mas décadas (gráfico 1 y cuadro 1). Sólo hacia 1992 el producto industrial recuperó el nivel que teóricamen-

de publicación se agradece. Las opiniones aquí vertidas son estricta responsabilidad de los autores. 
GRAFICO

Chile: Evolución de la producción industrial, 1957-1993

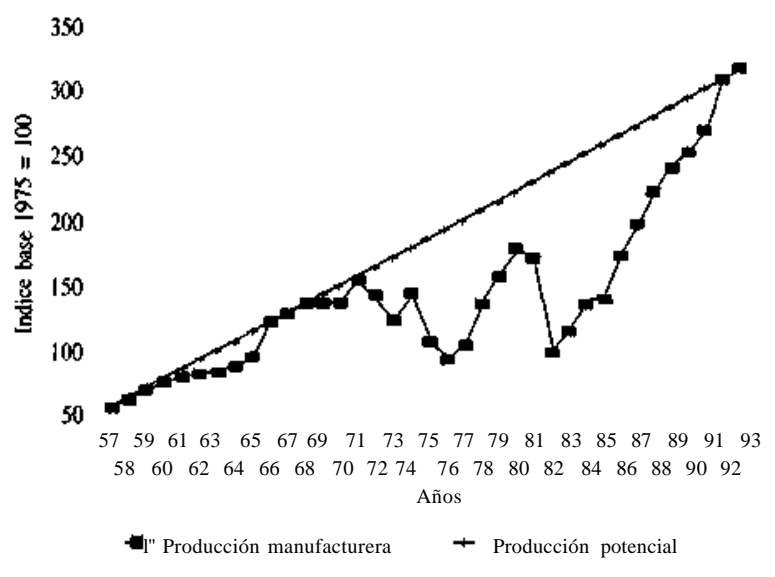

CUADRO 1

Chile: Variación media de la producción industrial en diferentes períodos entre 1958 y 1993

(Porcentajes)

\begin{tabular}{lr}
\hline Períodos & Tasas \\
\hline $1958-1993$ & 4.27 \\
$1958-1973$ & 4,40 \\
& \\
1974-1992 Fase de mercado & 4.50 \\
1973-1976 Crisis 1 & -11.52 \\
1977-1981 Recuperación de la crisis 1 & 7.34 \\
1982 Crisis 2 & -33.74 \\
1983-1992 Recuperación de la crisis 2 & 11.31 \\
1989-1993 Etapa de recuperación & 11.77 \\
1992-1993 & 17.32 \\
\hline
\end{tabular}

Fuente: INE, varios años.

te habría alcanzado a partir de una extrapolación simple de lo ocurrido en los años setenta. En ese lapso hubo subutilización y destrucción de capacidad instalada, lo que significó el cierre de plantas fabriles, desempleo y desperdicio de capacidades técnicas acumuladas por la sociedad. En los últimos años considerados en el gráfico - 1991 a 1993 — la industria aceleró su ritmo expansivo.

De este extenso período destacaremos tres etapas bien diferenciadas: 1974-1981, 1982-1986 y la fase de resurgimiento y aceleración del ritmo expansivo en 1987-1994.

\section{Etapa 1974-1981}

Tras el golpe militar de 1973 se inició "...una de las más dramáticas reformas económicas que se hayan registrado en la historia de Chile" (Corbo y Sánchez, 1992). Los cambios tuvieron por objeto impulsar el tránsito hacia un modelo de organización social más desregulado y abierto a la competencia externa, guiado básicamente por señales del mercado. Esta transición se dio en un ambiente de recesión económica y de fuerte represión social.

Diversos economistas chilenos han intentado explorar las consecuencias económicas de semejante cambio paradigmático. Así, Mizala (1992) demuestra que no fue sólo la apertura externa de la economía lo que afectó al sector manufacturero, sino que también la caída de la demanda interna contribuyó en forma determinante a que bajara el nivel de actividad industrial del país en esos años. En efecto, en un contexto en el que era difícil expandir las exportaciones como conducta contracíclica, la caída de la demanda interna aparece como factor principal del descenso de la producción manufacturera nacional. Sólo más tarde, entre 1979 y 1981, las importaciones agregan un nuevo motivo de preocupación para las empresas locales. Esto indica que la sustitución de bienes de fabricación local por productos importados no ocurrió de manera inmediata tras la baja de aranceles, como a veces se supone en los modelos de ajuste macroeconómico, sino que tomó tiempo para que las importaciones llegasen a actuar como elemento disciplinador de los empresarios locales. En 1982, nuevamente la recesión y la caída de la demanda interna afectaron negativamente al sector.

V. Corbo clasifica las políticas de reforma estructural de esta época en cinco grandes grupos: i) las destinadas a eliminar controles de precios en los mercados de bienes, ii) las de liberalización del mercado financiero, iii) las de flexibilización de los mercados laborales, iv) las de control y disminución del déficit fiscal y v) las de reducción de la participación del Estado como productor de bienes y servicios (Corbo y Sánchez, 1992).

Los esfuerzos de estabilización macroeconómica y de reforma estructural previamente mencionados influyeron en el desempeño del sector manufacturero chileno en diversos planos:

i) La industria en su conjunto perdió aproximadamente $20 \%$ de participación en el PIB, pasando de $25.4 \%$ en 1970 a $21.5 \%$ en 1980 y a $20 \%$ en 1982 .

ii) La tasa efectiva de protección cayó fuertemente hasta alcanzar un promedio de $14 \%$ en $1979 . '$

\footnotetext{
${ }^{1}$ El aumento relativamente pequeño de las exportaciones de la CTI se explica por la escasa competitividad inicial de esta firma ante las avanzadas prácticas internacionales.
} 
iii) El funcionamiento general del mercado de trabajo cambió radicalmente con la prohibición de toda actividad sindical.

iv) El número de empresas industriales bajó en 13\% entre 1967 y 1979 (Mizala, 1992), afectando principalmente al grupo de pequeñas y medianas empresas de origen familiar; aumentó fuertemente la competencia externa, y el empleo industrial cayó en forma dramática.

v) Las industrias más afectadas por la competencia de los productos importados fueron las de los sectores 32, 36 y 38 de la Clasificación Internacional Industrial Uniforme (CIIU) que corresponden a textiles, fabricación de productos minerales no metálicos, exceptuados los derivados del petróleo y del carbón, y la fabricación de productos metálicos, maquinaria y equipo. Además, "En términos de rentabilidad, las empresas competitivas con las importaciones tuvieron el peor desempeño, lo cual era previsible dadas las condiciones adversas que debieron enfrentar esas compañías durante todo el período" (Mizala, 1992). Se destacan del resto las empresas orientadas al sector de los recursos naturales, que se beneficiaron de la apertura comercial.

Para adaptarse al nuevo marco económico, ${ }^{2}$ las empresas optaron por:

i) Racionalizar el estilo de gestión y organización del trabajo con que operaban, disminuyendo la variedad de productos que fabricaban e incrementando el componente de insumos importados por unidad de producto, con lo cual mejoraron la productividad laboral y las utilidades sin efectuar grandes inversiones en nuevos equipos. ${ }^{3}$

ii) Mejorar la calidad de los productos, reduciendo la nómina de los fabricados localmente y ampliando la gama de los ofrecidos al mercado mediante la importación de aquellos que no producían. Para las empresas exportadoras de commodities industriales el cambio en estrategias de producción fue mínimo.

iii) Cambiar la composición de sus activos, transformando sus activos físicos en activos financieros y prefiriendo la especulación a las inversiones reales en maquinaria y equipo. El nivel de endeudamiento aumentó, al principio en pesos y luego en dólares, y los

\footnotetext{
${ }^{2}$ Cabe destacar que nos referimos al promedio sectorial. Obviamente hay actividades particulares que se comportan de manera distinta (véase, Agacino, Rivas y Román, 1992).

3 Aunque sólo hay muestras de aumentos de eficiencia entre 1974 y 1979, puesto que después se observó una caída hasta 1986 (Marshall, 1992).
}

inventarios se redujeron a un mínimo. A. Mizala argumenta que el problema financiero fue el que más afectó a las empresas y que muchas de las que quebraron lo hicieron porque no lograron adaptarse por el lado financiero (CEPAL/CIID, 1995).

En resumen, la apertura comercial y las políticas de estabilización macroeconómica llevaron a las empresas a esforzarse por racionalizar la organización del trabajo. Las firmas que sobrevivieron tendieron a transformarse en ensambladuras de partes y componentes importados, y a completar su línea de ventas con productos íntegramente desarmados (CKD) traídos del exterior. Las ramas procesadoras de recursos naturales tendieron a ganar terreno en términos relativos dentro de la estructura industrial, en detrimento de las ramas dedicadas a la producción para el mercado interno.

\section{Etapa 1982-1986}

En Chile, al igual que en el resto de América Latina, estos fueron años de profundo desequilibrio externo causado por el aumento de las tasas internacionales de interés, la caída de la relación de precios del intercambio y la ausencia de financiamiento internacional tras la moratoria mexicana de 1982. Estos hechos generaron una rápida expansión de la deuda externa y forzaron a los distintos gobiernos a buscar financiamiento en el ámbito interno, con el consiguiente impacto inflacionario.

En estos años, la economía chilena estaba abierta a la competencia externa y era muy sensible a las perturbaciones desde el exterior. Las medidas que adoptó la autoridad económica fueron básicamente las de cerrar parcialmente la economía y aplicar políticas expansivas contracíclicas. Se buscó manejar "el tipo de cambio como principal instrumento para enfrentar el desequilibrio externo, complementado por aumentos en el nivel de aranceles" (Meller, 1992). Además, se volvió a controlar algunos precios (de los productos agrícolas, por ejemplo) y la tasa de interés, junto con la expansión del gasto público.

El PIB bajó $14 \%$ en 1982 y $0.7 \%$ en 1983 . En ese mismo año, el desempleo aumentó a un $28.5 \%$ y las importaciones cayeron a menos de la mitad de la cifra de 1981. Se inició la recuperación del sector externo de la economía. En el ámbito manufacturero, el producto disminuyó en 1982 un $21 \%$ y el empleo un $27 \%$. Comenzó un período de fuerte desinversión que culminó en 1984, cuando la inversión cayó un $45 \%$ con respecto a los niveles de 1979 . El sector de la peque- 
ña y mediana empresa (PYME) fue el más sensible a los cambios, con lo cual aumentó su rezago con respecto a las grandes empresas. El cambio en la política cambiaria mejoró la rentabilidad del sector orientado a la exportación y sustentado en los recursos naturales.

Con las medidas proteccionistas mejoró la rentabilidad de las ramas productivas dedicadas al mercado interno, aunque en un clima general de incertidumbre y desaliento en cuanto a la inversión en estos sectores. La actividad productora de commodities industriales fue la que tuvo un desempeño particularmente expansivo. En el resto de las ramas productivas predominó la pérdida de dinamismo.

En resumen, este período se caracterizó por un alto grado de desequilibrio y turbulencia macroeconómicos. Abundaron las quiebras de empresas. Ganó terreno en términos relativos la industria elaboradora de materias primas y creció el grado de concentración económica prevalente al interior del sector manufacturero, ante el fracaso relativo de las PYME para adaptarse a las nuevas condiciones del entorno macroeconómico.

\section{Período 1987 al presente}

Se reinicio la apertura comercial con una rebaja de aranceles y la economía se recuperó y empezó a crecer. Esto ocurrió en un ambiente de cambio en el régimen político. Se replanteó la necesidad de cuidar los objetivos sociales, pero respetando las restricciones del equilibrio macroeconómico. Teniendo esto en cuenta se decidió aumentar los impuestos con el fin de no financiar gastos sociales con emisión de dinero ni con deuda pública. Permaneció sin ser cuestionada la idea de que el mercado es mejor asignador de recursos que la autoridad estatal, pero la desregulación no fue completa ni universal, ya que no se aplicó en la actividad financiera, la explotación del cobre, etc. El gobierno de Frei Ruiz-Tagle mantuvo esencialmente la misma concepción de la organización social que su antecesor en el poder.

Según algunos autores, una cuarta parte de la expansión alcanzada en esta etapa se debió al crecimiento de la demanda interna, y casi dos tercios a la apertura exportadora (Agacino, Rivas y Román, 1992). En estos años las empresas terminaron de sanear su situación financiera.

El panorama económico global experimentó claros signos de mejora. Siguió declinando la inflación, se elevó el ritmo de crecimiento, aumentó la inversión, ingresaron capitales externos en proporción creciente, la tasa de ahorro interno se acrecentó, y los salarios reales y las exportaciones subieron. A la vez comenzó a observarse una visible apreciación del tipo de cambio real.

En el sector manufacturero mejoró el nivel de empleo industrial. La inversión se elevó, pero sólo en 1988 recuperó su nivel de 1979, y en 1989 el de 1981.

A partir de 1988 las exportaciones manufactureras se diversificaron y siguieron ampliándose, indicando con ello que el vuelco del sector hacia el exterior iba aumentando a pesar de la apreciación del tipo de cambio real.

Las estrategias empresariales (Castillo, Maggi y Dini, 1994) se concentraron en los siguientes aspectos:

i) Gestión. Crece la profesionalización de los elencos gerenciales y el trabajo en equipo. Las tendencias dominantes apuntan a la reducción y flexibilización de la estructura jerárquica y a la incorporación de nuevas funciones asociadas al manejo informático.

ii) Crecimiento. Se observan al menos tres estrategias distintas: la ampliación de las plantas, la creación de plantas nuevas y la adquisición o take-over de empresas existentes. Esto se hace en la mayoría de los casos con fondos propios, aun cuando la mayor parte de las empresas considera expedito el acceso al mercado financiero.

iii) Recursos humanos. Los sindicatos siguen teniendo muy escasa participación en las decisiones de modernización. Comienzan a utilizarse los incentivos fiscales para la capacitación.

iv) Tecnología. Se acentúan los esfuerzos de diseño de producto, tratando de llegar a consumidores diferenciados y a ciertos nichos de mercado. Los cambios en la producción se basan en la compra de maquinaria y en la adaptación de la tecnología adquirida en el exterior a la escala del mercado chileno. No hay grandes preocupaciones por disminuir tiempos muertos a través de la realización de métodos y tiempos de trabajo.

v) Comercialización. Se busca la diferenciación de productos, el posicionamiento de mercado por vía de las marcas, la calidad y el desarrollo de servicios a clientes y redes de distribución preferenciales. Además, se realizan alianzas comerciales y se diversifican las áreas de negocios. El nivel de subcontratación es bajo.

En resumen, a partir de 1985 la industria creció con la incorporación de factores productivos, sobre todo mano de obra, a diferencia de lo ocurrido en la etapa anterior, que fue ahorradora de mano de obra en términos absolutos. Por este motivo la productividad la- 
boral no aumentó significativamente. Sin embargo, en el último trienio asistimos aparentemente al inicio de un dinamismo mayor que el de épocas anteriores, lo que se traduce en la incorporación más acelerada de equipos de comando numérico, de sistemas CAD y CADCAM, de tecnologías automáticas para el control de los procesos, de alguna robótica, etc. Pese a ser recientes, estos hechos parecen sugerir una aceleración del crecimiento manufacturero chileno.

Algunos aspectos merecen ser destacados. Hay indicios de que las exportaciones industriales se están diversificando y expandiendo a la par con el repunte en los últimos años de la inversión industrial. También de que la subcontratación se está profundizando. Si se estudia la industria por ramas, se aprecia que el sector exportador es el que ha desarrollado mayor dinamismo y ha alcanzado más peso relativo en la producción manufacturera, pero que el sostenido ritmo de crecimiento de la economía ha hecho que las industrias dedicadas al mercado interno también mejoren su proceso de expansión. El empleo, mientras tanto, ha mostrado cierta tendencia al estancamiento relativo.

Esto revela que el proceso de recuperación de la industria en los años ochenta se llevó a cabo reasignando recursos desde ramas dedicadas al mercado interno hacia otras que hacen uso más intensivo de capital y producen commodities industriales de exportación. En cuanto a morfología de los mercados, observamos dos hechos importantes: en los bienes de consumo aumentó la competencia en el medio local, en tanto que en los mercados de commodities industriales la oferta provino de un reducido núcleo de grandes grupos corporativos fuertemente volcados al negocio de exportación.

\section{Desarrollo evolutivo de una empresa metalmecánica: el caso de la CTI}

En esta sección se describe la evolución de una firma productora de artículos del hogar (refrigeradores), distinguiendo tres etapas distintas a lo largo de las últimas décadas (gráfico 2).

En la actualidad la firma es una sociedad anónima abierta que produce cocinas, refrigeradores, lavadoras de ropa y estufas, bajo las marcas Fensa, Madem-

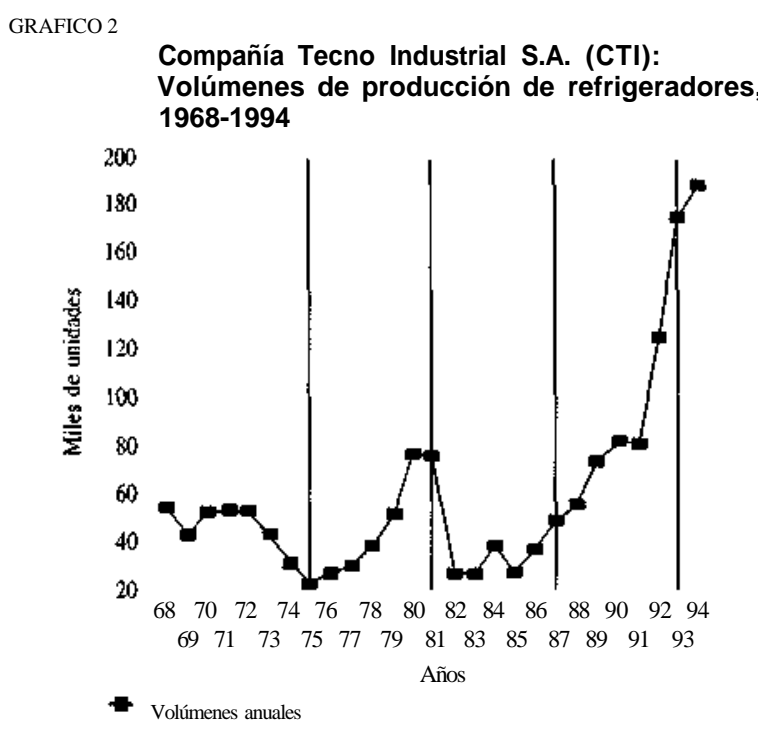

sa y Ferriloza. Además, comercializa una extensa gama de aparatos electrodomésticos que no produce por sí misma.

La firma se relaciona con más de 50 proveedores (entre ellos muchos del exterior: de Bélgica, Brasil, Italia y Japón). Emplea alrededor de 1400 trabajadores y opera básicamente como empresa ensambladura, en la que el $70 \%$ del costo de fabricación corresponde a importaciones de partes y componentes.

Tras estos breves elementos introductorios vayamos ahora al estudio de su proceso evolutivo

1. Etapa de expansión y reorganización fabril (1975-1981)

a) Organización de la producción e ingeniería de procesos

Tras la reprivatización de la firma se inició su reestructuración, buscando alcanzar economías de escala y especialización a través del paso desde la producción por lotes a la de trabajo en línea.

La fusión Fensa/Mademsa ocurrida en 1975 dio origen a la actual cu - Compañía Tecno Industrial S.A.- y concentró toda la producción en la planta de 
Fensa ubicada en Maipú. ${ }^{4}$ La fusión se realizó con el fin de enfrentar la apertura comercial, que vaticinaba una mayor competencia externa. Antes de la fusión, Mademsa estaba compuesta de cuatro plantas distribuidas en tres localizaciones distintas, las que a comienzos de 1975 empleaban unas 2000 personas.

Fensa, en cambio, tenía una sola planta fabril en Maipú, instalada de manera más racional y ordenada en la que empleaba aproximadamente 1900 personas.

La fusión provocó una reducción de personal: 1500 trabajadores se acogieron a retiro voluntario, en un clima de gran tensión obrero/patronal. Las relaciones entre la empresa y el sindicato pasaron por una etapa muy conflictiva.

Quizás el hecho técnico más interesante sea la rápida preponderancia del modelo organizacional de producción en línea por sobre el de producción en lotes. En Mademsa el gerente general negociaba con cada operario un contrato informal que establecía el producto esperado de él y la remuneración prevista. Esto hacía que existiera una infinidad de contratos dentro de la planta y que cada operario tuviera cierta libertad para diseñar su propio proceso productivo, desarrollando dispositivos e instrumental propios para llevar a cabo su tarea. Cada uno de los trabajadores era un artesano del metal que cubría con facilidad una extensa gama de subprocesos metalmecánicos, como estampar, soldar, tornear, etc. No había departamento de métodos y tiempos puesto que era el mismo trabajador quien debía mejorar su tiempo de producción, captando así los beneficios de su mayor productividad.

En Fensa, el modelo de organización de la producción era muy distinto y mucho más convencional. Se producía en línea y el operario recibía premios por rendimientos superiores al esperado. El trabajador no tenía autonomía para organizar su trabajo ni debía construir sus propias máscaras y dispositivos; tampoco era responsable por el producto global, sino por una tarea específica. Dependía rígidamente de un sistema de tiempos y movimientos, y la programación de la producción era mucho más detallada y controlada, sobre la base de métodos taylorianos de organización.

Como vemos, en la fusión Fensa/Mademsa se confrontaron dos modelos organizacionales diferentes y dos 'culturas' empresariales distintas. Una de las dos habría de preponderar y en este caso fue el modelo

\footnotetext{
${ }^{4}$ Mademsa fue absorbida por Fensa, hecho que probablemente se explica por los menores rendimientos de aquella debidos a su producción en lotes chicos, frente a los de la organización productiva 'en línea'.
}

Fensa el que se impuso. Naturalmente, la asimilación de las diferencias tomaría tiempo y sólo hacia 1979 se produjo la fusión total del sistema bajo el modelo FENSA. Fue necesario prohibir a los ex trabajadores de Mademsa construir sus propias máscaras y dispositivos de trabajo, con lo cual se perdió la formación artesanal que ellos traían de su historia laboral previa.

En el período 1973-1976 se avanzó en la reorganización de los procesos productivos. Pese a ello, según un informe todavía en 1977 la planta fabril era bastante irracional, puesto que las estaciones de trabajo no estaban bien delimitadas, las herramientas no estaban normalizadas, existían líneas de armado paralelas a la línea central de trabajo, se empleaba mucho tiempo en la manipulación de materiales y había muchas zonas de la línea donde se demoraba el flujo productivo.

En el ámbito de la gestión administrativa también se intentó mejorar la organización del trabajo con la introducción de la computación en 1977. Este cambio demoró muchos meses y provocó el despido de cerca de 60 empleados administrativos.

Como muchas otras empresas chilenas, la CTI confrontó un importante crecimiento de la demanda interna en 1979-1980. En ese momento la firma chocó con los límites de la capacidad instalada y decidió desverticalizar la producción y dedicarse sólo a la fase final del montaje de refrigeradores. A raíz de ello la gerencia hubo de montar un complejo mecanismo de compras de partes y subconjuntos en el mercado internacional, dando comienzo así a un nuevo modelo de organización del trabajo basado en el ensamble de componentes importados.

En 1980 y 1981 se compraron termoformadoras más eficientes, lo que llevó a reducir el plantel de operarios en cerca de 20 personas. Se dejó de producir evaporadores, que comenzaron a importarse desde Japón, así como también filtros y condensadores, que comenzaron a traerse de Italia. Se vendió la planta de motocompresores a Brasil, y se transfirió la producción de calefactores eléctricos a Fabritel, la de parrillas a Lioy y Ferromat, la de motores a Somela, y así sucesivamente.

Con este proceso de desverticalización la firma se concentró en un número menor de actividades, quedándose con las más rentables.

Hasta el inicio de los años ochenta los ingenieros y técnicos no estaban claramente especializados por líneas de productos. Cada ingeniero trabajaba en varias líneas, perdiendo así economías de especialización. A fines de 1980 se estableció una organización más es- 
pecializada, con una orientación clara hacia productos específicos, al crearse cuatro departamentos de ingeniería: de refrigeradores, de estufas de cocinas, y de lavadoras.

Esta reestructuración permitió reducir el número de trabajadores de 2500 en 1975 a 1300 en 1980.

\section{b) El diseño de productos}

En materia de diseño de productos es poco lo que la empresa realizó hasta ya iniciados los años ochenta. En 1981 todavía no se fabricaban refrigeradores de dos puertas, de modo que se intentó desarrollar un producto local de esas características, copiando un modelo alemán ya antiguo. Desde su concepción hasta la puesta en producción el proyecto demoró dos años, de modo que el refrigerador comenzó a producirse en junio de 1982. La gama de modelos fabricados se redujo de nueve a cuatro, importándose el resto de los rubros que se comercializaban.

Resumiendo, puede decirse que en esta primera etapa de su historia de adaptación a los cambios de la macroeconomía la empresa buscó economías de especialización, reduciendo la gama de productos fabricados, trasladando toda la producción a una planta, disponiendo las instalaciones fabriles en línea, reduciendo el grado de integración vertical y de autofabricación de partes y subconjuntos, aumentando el contenido importado, haciendo mayor uso de subcontratistas, reorganizando los procesos de trabajo e introduciendo la computación en su sector administrativo. Asimismo, redujo la mano de obra empleada en casi $50 \%$, unificó el sistema de remuneraciones y eliminó la organización en talleres.

Estos cambios tuvieron resultados satisfactorios, según señalan los indicadores correspondientes (gráfico 3). La producción se duplicó y creció la productividad de la mano de obra. La empresa utilizó capacidad ociosa e introdujo mejoras organizacionales, pero no hizo grandes inversiones en bienes de capital. Su rentabilidad mejoró: desde 1979 muestra utilidades.

\section{La crisis de 1982-1986}

\section{a) Organización del trabajo e ingeniería de proce- sos}

En 1980-1981 culminó un ciclo expansivo. En 1982 la macroeconomía chilena entró en una fase de fuerte turbulencia. El volumen físico de producción de la firma experimentó una gran caída, hecho que sumado a malos negocios con empresas del exterior y a un alto nivel de endeudamiento la puso al borde de la quie-
GRAFICO 3

Compañía Tecno Industrial S.A. (CTI):

Evolución de indicadores, 1975-1981

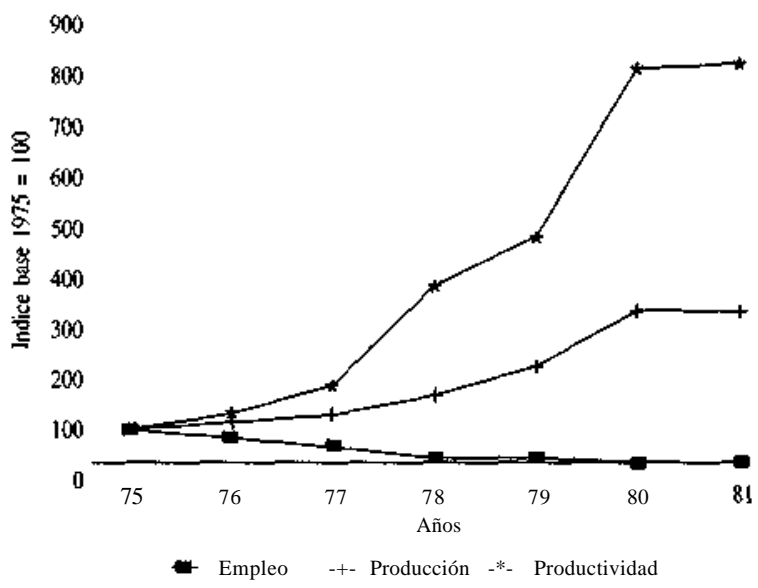

bra a comienzos de 1983, debiendo pasar a poder de los bancos acreedores.

Para enfrentar la crisis se tomaron las siguientes medidas: i) se inició una nueva ola de despidos masivos, que fue desde gerentes hasta operarios; ii) se comenzó a producir a pedido y para terceros al solo efecto de mantener en funcionamiento la planta, lo que llevó a reorganizarla para producir en lotes chicos, y iii) se volvió a la integración vertical de procesos que hacen uso intensivo de mano de obra a fin de tener ocupada la dotación de personal.

En 1985 la firma sólo ocupaba unas 300 personas.

A fines de ese año, la empresa comenzó nuevamente a repuntar. En un mercado global mucho más chico, su participación relativa mejoró marginalmente a expensas de su competidor local (Cimet/Sindelen) y de los muchos importadores que se retiraron masivamente del mercado local.

\section{b) El diseño de productos}

En un intento por superar la crisis se introdujeron diversas modificaciones en el diseño de productos. El número de modelos fabricados — cuatro en 1980se elevó a 13 en 1986. Hubo cambios de diseño, se sustituyeron partes y componentes de los refrigeradores por otros de diseño y fabricación propia en aluminio, y se construyó en planta una máquina manual para fabricar internamente los serpentines en dicho material, que previamente se importaban.

En síntesis, en esta segunda etapa el aumento de la tasa de interés y la devaluación del peso dieron por 
resultado una fuerte caída del volumen físico de producción de la firma y la llevaron a una crisis financiera. La empresa cambió de dueños, de estrategia productiva y de mercados.

Despidió a una gran proporción de su plantel obrero. Intentó diversificar su producción y volvió a trabajar a pedido en lotes chicos, para terceros. Retomó actividades que hacen uso intensivo de mano de obra con el fin de aprovechar su capacidad instalada, que estaba siendo muy subutilizada, y sólo marginalmente intentó la exportación como medida contracíclica. La gama de productos fabricados pasó de cuatro a 18. En definitiva el producto y el empleo cayeron, la productividad del trabajo subió ante la fuerte reducción del número de operarios y la firma vivió una etapa de gran turbulencia e inestabilidad.

\section{La expansión de 1987 en adelante}

\section{a) Organización de la producción e ingeniería de procesos}

En 1987 la CTI cambió nuevamente de dueño. Poco tiempo más tarde se decidió la construcción de una nueva planta de refrigeradores que produciría 200000 unidades al año. Se estimaba que esa sería la demanda interna hacia fin de siglo.

En 1989 se comenzó a preparar la puesta en marcha del programa de expansión. Se modificó la estructura de gestión de la empresa, creando las gerencias de producción y la de ingeniería y desarrollo. En 1990, los nuevos propietarios invirtieron cerca de 5 millones de dólares en la construcción de una nueva planta fabril. Se instaló un moderno equipo automatizado de fosfatizado y pintura para enfrentar el principal "cuello de botella" en la línea de producción. Se duplicó el volumen de ocupación y el de producción. La nueva planta, con una superficie aproximada de $9000 \mathrm{~m}^{2}$, se puso en marcha en abril de 1991.

El crecimiento de la demanda superó fuertemente lo previsto y la firma debió enfrentar problemas organizacionales inesperados, lo que explica su desordenado crecimiento durante los últimos años. Son pocos aún los subprocesos automatizados.

A partir de 1993, la compañía intentó mejorar el nivel medio de capacitación de su personal a través de charlas, talleres, etc.

\section{b) El diseño de productos}

En el último lustro de los años ochenta la firma avanzó poco en materia de ingeniería de productos. Se siguió produciendo un refrigerador híbrido, de dos
GRÁFICO 4

Compañía Tecno Industrial S.A. (CTI):

Evolución de indicadores, 1987-1994

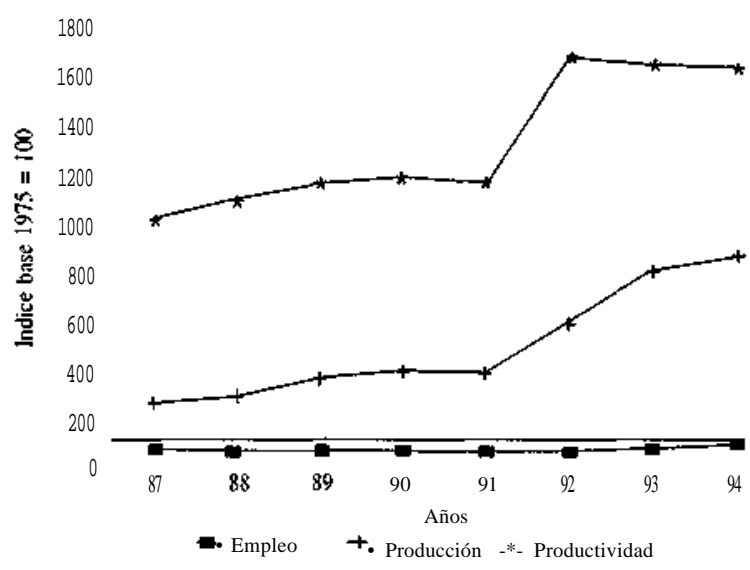

puertas, usando el diseño básico y hasta los moldes de modelos 'viejos'. El número de modelos siguió aumentando hasta llegar a 18 en 1989, y entonces comenzó a disminuir, bajando a 14 en 1991. En este último año la firma empezó a utilizar el sistema CAD en el diseño de nuevos productos, pero los tiempos de diseño siguen siendo sustancialmente mayores que los que alcanzan fabricantes internacionales de primera línea.

En 1994 la nueva planta ya estaba trabajando a plena capacidad con dos turnos y hasta tres en determinados subprocesos. En algunos de los subprocesos se emplea tecnología avanzada y en otros técnicas anticuadas, a veces casi artesanales. Las placas de plástico se cortan con dos máquinas: una moderna, asistida por computador, con un sistema muy preciso de calentamiento y que produce con alta eficiencia y velocidad, y otra 'vieja' que funciona con rendimiento menor, con una varianza diez veces mayor en la fase de calentamiento y con menor eficiencia de corte.

La planta puede verse entonces como un conjunto de islas de gran modernidad en un escenario global en el que aún subsisten equipos, matrices de producto, conceptos organizacionales y otros elementos que son prototípicos de una planta fabril de dos o tres décadas atrás.

Pese a lo reciente de la puesta en marcha de la nueva planta fabril, hoy vuelve a plantearse el interrogante acerca de cuál es la estrategia más razonable de crecimiento hacia el futuro. Una reciente visita a establecimientos que producen refrigeradores en el sudeste asiático mostró a la firma que la frontera tecnológica internacional en ingeniería de procesos se caracteriza en nuestros días por la eliminación de las tareas 
de pintura y su reemplazo por chapas de acero ya pintadas, puestas en planta listas para el montaje del refrigerador. La sección de pintura volvió a transformarse en un cuello de botella por la rápida expansión de los volúmenes de producción, con lo cual volvió a plantearse nuevamente la disyuntiva de efectuar la futura expansión ya sea agrandando la sección de pintura, o sustituyéndola por una tecnología basada en la adquisición de chapa pintada. Lo que se decidió fue importar planchas de acero prepintado, lo que obligará a adquirir máquinas que trabajen con este tipo de planchas.

La empresa sudcoreana Samsung logra producir cerca de 120 refrigeradores por hora, esto es, el doble que la firma local, en un espacio físico más reducido. $\mathrm{Su}$ producción está organizada conforme al sistema de justo a tiempo, casi sin tiempos muertos. La planta chilena, en cambio, debe aún conseguir que el abastecimiento en línea sea constante, con un sistema eficien- te de bodegas. Con este fin, los materiales de importación se almacenan con un mes de anticipación.

Si comparamos a la firma local con sus competidores externos observamos lo siguiente:

i) Esta necesita aún cerca de dos años para llegar al mercado con un nuevo diseño de producto, y es relativamente poco lo que ha mejorado en esta materia a través del tiempo. Todavía funciona a base de la construcción de prototipos y su posterior ensayo experimental, aunque tenga ya un sistema AutoCAD que trabaja en dos dimensiones. Los productores japoneses, por ejemplo, se demoran menos de un año en el diseño de un nuevo producto, trabajan en tres dimensiones y pueden diseñar por simulación.

ii) La información obtenida sugiere que la firma va a la zaga de plantas japonesas, pero que el rezago es menor si comparamos con fábricas coreanas, las que a su vez están algo detrás de la mejor tecnología mundial.

\section{IV}

\section{El comportamiento microeconómico}

\section{y los cambios de la macroeconomía chilena}

En las secciones anteriores de este trabajo hemos examinado, por un lado, la evolución histórica del sector manufacturero chileno y, por otro, las sucesivas reestructuraciones de una planta metalmecánica productora de refrigeradores que tuvo que ir adaptándose a los cambios del marco regulatorio y el régimen de incentivos prevalecientes en el país. En este esfuerzo de adaptación la firma fue recreando conductas que en muchos sentidos reflejan comportamientos más generales que es dable observar en muchas otras empresas chilenas. En este sentido, el estudio de casos adquiere un valor descriptivo que trasciende al caso individual. En esta sección intentaremos reunir el caso de la firma individual con las variables de conjunto a fin de estudiar los complejos vínculos micro/macro que subyacen el proceso de ajuste estructural de la economía chilena. Comenzaremos empleando instrumentos convencionales de teoría de los precios, para luego avanzar hacia un marco interpretativo algo más amplio que nos permita incorporar ideas recientes de teoría evolutiva de raíz schumpeteriana.

\section{Algunos rasgos centrales del caso estudiado vistos desde la teoría microeconómica conven- cional.}

Desde la perspectiva de la teoría microeconómica convencional el presente estudio de casos muestra:

i) la traslación y rotación de la curva de demanda en función de efectos precio e ingreso derivados de cambios en los gustos de los consumidores, en la distribución del ingreso, en el grado de competencia externa que enfrenta la empresa, etc;

ii) la traslación y rotación de la curva de costos ante la caída de los salarios reales, la baja del costo de capital y el impacto del cambio tecnológico desincorporado y las economías de escala.

Para los efectos del análisis, es importante recordar que la firma cambió varias veces de dueño y de estrategia, y que al hacerse cargo de su conducción cada elenco propietario traía su propia visión del panorama general de la economía chilena, y del papel que asignaría a esta empresa dentro del grupo económico como un todo. 
En un caso, la firma funcionó como captadora de fondos que serían utilizados mayoritariamente en otras actividades empresariales. En otro, los bancos acreedores en cuyas manos quedó la firma tras su falencia comercial en 1982 buscaron recuperar el capital invertido en ella. Finalmente, el grupo que tomó el control de la en en 1987 tenía objetivos más cercanos a la idea convencional de modernización tecnológica y de gradual aumento de la eficiencia técnica que normalmente se asocia con el comportamiento de una empresa en condiciones de estabilidad macroeconómica y buen funcionamiento de los mercados de factores. En otros términos: sólo desde 1987 puede hablarse de una estrategia de largo plazo propiamente dicha.

2. La situación macroeconómica y el comportamiento de la firma desde la perspectiva de la teoría económica convencional

Empleando el instrumental convencional de la teoría de los precios podemos representar lo ocurrido en este caso de la siguiente manera (gráfico 5). La CTI actúa como firma grande, monopolista, fijando precios en el tramo de costos marginales crecientes, en tanto que sus competidores más chicos $(\mathrm{CH})$ operan como empresas indiferenciadas con costos marginales constantes. Los importadores $(\mathrm{OM})$ tienen costos constantes. Si el arancel externo es muy alto simplemente se quedan fuera del mercado. La situación inicial antes de la apertura se visualiza así: la empresa "establece" el precio de mercado en peti y produce QCII Las pequeñas empresas producen $\mathrm{QCH}$ adoptando el precio establecido por la CTI. La cantidad total producida es Qt.

En 1975, al reprivatizarse la empresa, ésta buscó reorganizar su funcionamiento tras el conflictivo pe-

GRAFICO 5

Compañía Tecno Industrial S.A. (CTI): Situación antes de la apertura

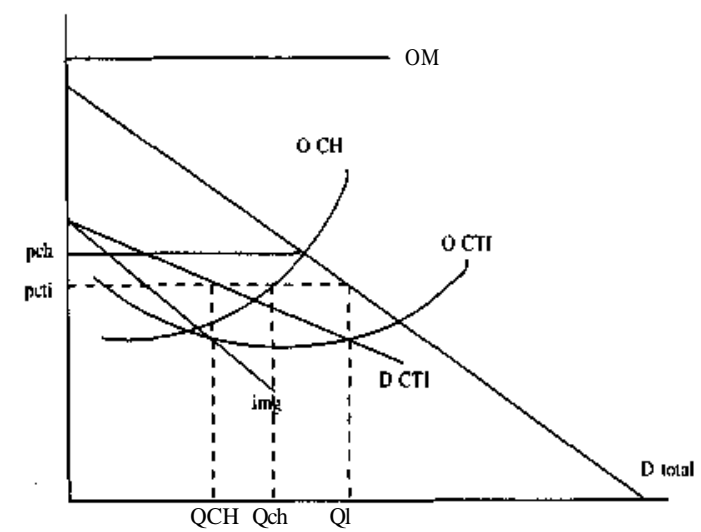

ríodo en que permaneció en el área de propiedad social, fusionándose con otra empresa para lograr economías de escala y especialización; racionalizó los procesos y la gama de productos que fabricaba e introdujo algunos cambios en la tecnología de producción; privilegió comportamientos especulativos, se endeudó, y no optó por una profundización tecnológica de largo alcance; expandió su volumen físico de producción y mejoró su productividad laboral, reduciendo la nómina de trabajadores.

En el curso de los años 1975 a 1982 la firma sufrió el impacto de diversas perturbaciones provenientes del ámbito macroeconómico: i) la recesión global que afectó a la economía chilena con motivo del programa de estabilización macroeconómica; ii) la apertura comercial con apreciación del tipo de cambio real; iii) el incremento de las importaciones de bienes sustitutivos; iv) una mayor demanda interna de los estratos de altos ingresos y el cambio consiguiente en los gustos de los consumidores y v) el alza de la tasa de interés. Los efectos de estas perturbaciones se tradujeron, como dijéramos antes, en la traslación y rotación de la curva de demanda, la variación de la curva de costos, la caída del nivel real de protección externa, etc. (gráfico 6).

Los costos de los importadores se redujeron (de $\mathrm{OM}$ a OM2). La función de demanda se trasladó hacia el exterior y rotó con respecto a su eje, volviéndose más elástica y reflejando el proceso de concentración de los ingresos. Se pasó de D total a D total2. La demanda que enfrentó cada competidor fue más elástica, puesto que la variedad de la oferta creció con la entrada de los importadores. Fueron éstos los que fijaron el precio de mercado en p. Las empresas nacionales racionalizaron su producción, tratando de despla-

GRÁFICO 6

Compañía Tecno Industrial S.A. (CTI): Situación después de la apertura, 1975-1981

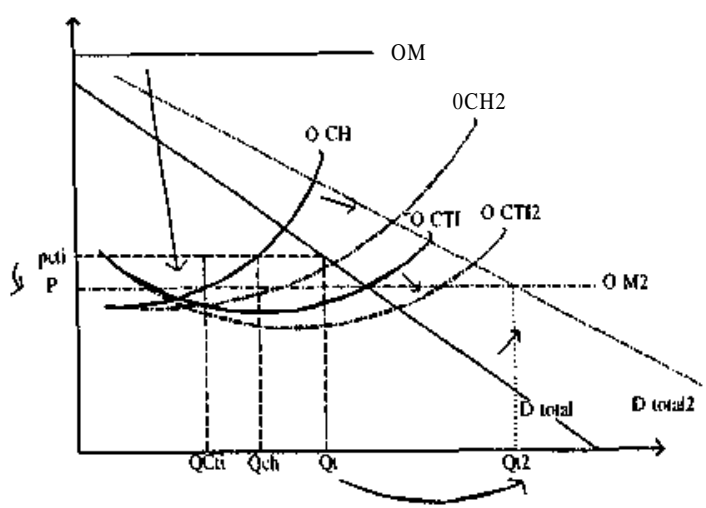


zar hacia abajo su curva de costos marginales. Varios competidores nacionales quedaron eliminados del mercado: es decir, se pasó de OCTI a OCTI2 pero no se logró fabricar refrigeradores a costos más bajos que los de importación. La participación de la CTI descendió hasta al $30 \%$ del mercado, en tanto que los importadores llegaron a cubrir $60 \%$ del mercado. Al fijar el precio de las importaciones por debajo de la curva de costos de las empresas nacionales cabía suponer que todas éstas dejarían el mercado. Algunas lo hicieron, pero otras no, y algunas lograron sostener su presencia gracias a factores como marcas o prestigio acumulado.

Con la crisis financiera de comienzo de los años ochenta, cambió radicalmente la estrategia de la firma, que llegó a dicha coyuntura fuertemente endeudada debido al papel de proveedora de fondos que debía cumplir como parte de la estrategia global del grupo que la controlaba.

En ese momento - $\mathrm{y}$ con un mercado interno en franca contracción, lo que hizo que la demanda se desplazara de D total2 a D total3 (gráfico 7\} — se optó por desarmar la estructura organizacional prevalente y por trabajar en lotes chicos y como subcontratista de terceros, buscando mantener utilizada la escasa mano de obra que se había preservado y las instalaciones físicas. Al plan de producción se reincorporaron actividades y procesos eliminados pocos años antes. Ante la gran incertidumbre reinante, los competidores externos se retiraron (OM2 a OM3), con lo cual, paradójicamente, la firma mejoró su posición relativa en el mercado pese a que la demanda interna era mucho menor. La CTI volvió a liderar la oferta y a fijar precios en el mercado interno, los que las firmas nacionales 'chicas'

GRÁFICO 7

Compañía Tecno Industrial S.A. (CTI): Efectos de la crisis de 1982

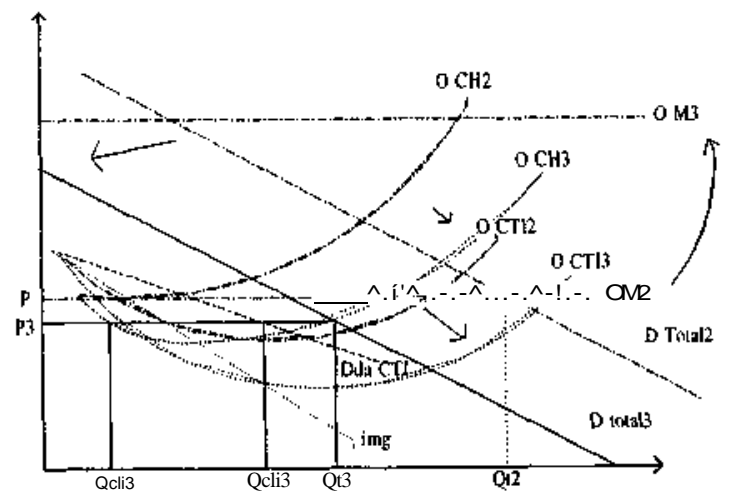

tomaron como un dato de mercado. Las cantidades fabricadas cayeron de Qt2 a Qt3.

A medida que pasaron los años la economía chilena comenzó a estabilizarse y avanzó hacia la recuperación. Creció nuevamente la demanda interna con el aumento de los salarios; disminuyeron los impuestos, las tasas de interés bajaron y el PIB continuó su ciclo ascendente.

La demanda de refrigeradores aumentó de $\mathrm{D}$ total3 a D total4 (gráfico 8). Mejoró la situación financiera de la empresa, lo que indujo a los bancos a venderla cuando pudieron recuperar su inversión original. Los competidores externos comenzaron a volver, pero ahora la CTI ya no perdió participación relativa en el mercado, como en el ciclo anterior de apertura, sino que logró sostener una alta participación en la demanda global.

¿Qué hizo que la firma lograra mantener su competitividad de largo plazo, aun cuando no ha introducido grandes cambios ni modernizado significativamente la tecnología de sus productos o sus métodos de trabajo? La respuesta a este interrogante proviene tanto del plano macroeconómico como del ámbito microeconómico.

Por el lado macro es evidente que con el rápido crecimiento global de la economía chilena el mercado interno se ha expandido con relativa rapidez, dando espacio a firmas locales ya establecidas que, entre otras ventajas, tienen reputación, marca y servicio de posventa con los que pueden competir con la oferta extranjera.

Por el lado micro resulta claro que la firma ha ido acumulando capacidad tecnológica propia, un acervo de habilidades técnicas en ingeniería de productos y

GRÁFICO 8

Compañía Tecno Industrial S.A. (CTI): Efectos de la recuperación de 1987-1994

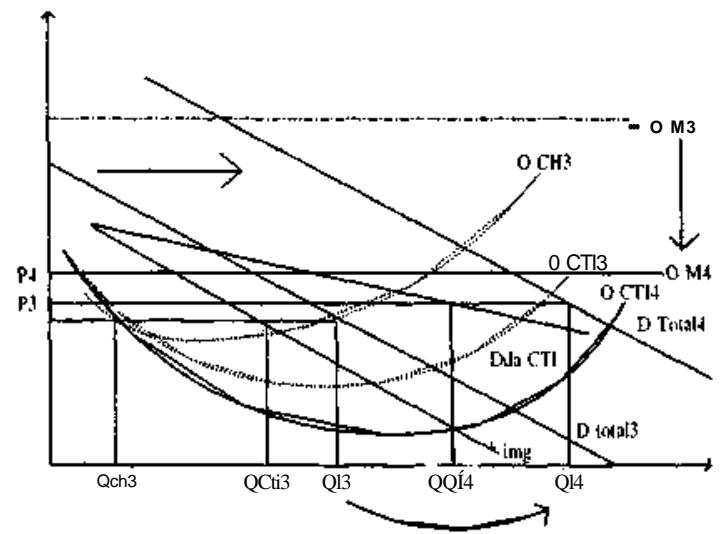


procesos lo que le ha permitido enfrentar con éxito la competencia externa. Es lo que sucede ahora que la empresa ha reducido significativamente su nivel de integración vertical y su aprovisionamiento interno de partes y componentes, y ha concentrado sus operaciones en el montaje de subconjuntos y piezas en buena medida importadas a precios internacionales. La CTI ha aprendido a comprar (desde fines de los años setenta) y a vender, diferenciando mercados, en las épocas de crisis. También ha adquirido flexibilidad en la organización y el manejo de su fuerza de trabajo, con lo cual ha podido alcanzar competitividad sin haber incursionado en grandes programas de modernización tecnológica ni haber hecho fuertes inversiones de capital. La administración se maneja con austeridad y los costos de la mano de obra representan apenas el $10 \%$ del costo total — como en las firmas competidoras extranjeraslo que le da una buena capacidad de respuesta frente a la competencia externa.

También ayuda a su sobrevivencia un tercer factor que llamaremos "efecto distancia". Siendo Chile un mercado pequeño y relativamente alejado de los grandes mercados mundiales disfruta de cierta protección natural: los costos de transporte y la dificultad de montar un servicio de posventa eficiente protegen a los fabricantes locales de la competencia externa. Así quedó demostrado en los años ochenta, cuando los competidores externos abandonaron el mercado local sin pensar mayormente en el mantenimiento del parque de equipos vendidos en el país. El mercado, que aprendió a tomar en cuenta este factor de riesgo, otorga importancia a los productores locales comprometidos con la asistencia técnica posventa.

En 1990 se relanzó la idea de construir una nueva planta, proyecto que había sido postergado por 14 años y que podría ser visto como una fuerte discontinuidad con el pasado, un gran salto técnico. En rigor no lo fue. Involucró, eso sí, un aumento significativo de capacidad instalada de producción, pero dentro del paradigma tecnológico y de organización del trabajo prevaleciente históricamente. La nueva planta no incorporó las prácticas internacionales más avanzadas en la materia. Se buscó disminuir los tiempos de fabricación pero sin recurrir a la automatización de los procesos, al manejo computarizado de inventarios, al transporte computarizado de partes y piezas en la planta.

La estabilidad macroeconómica ayudó a que la empresa encarara finalmente este programa de inversión que no había logrado materializar por casi dos décadas. Pero al hacerlo no puso en marcha una plan- ta fabril enteramente nueva, sino que se limitó a modernizar instalaciones preexistentes.

La incorporación de máquinas modernas y subprocesos automatizados junto a maquinaria y matricería viejas permitió mejorar la productividad, lograr economías de escala y alcanzar mayor flexibilidad operativa con bajos montos de inversión física. Pero sin duda dicho objetivo se alcanzó al costo de no constituir un programa completo de modernización que colocara a la firma en pie de igualdad técnica con establecimientos representativos del estado del arte mundial en esta materia. Tan es esto así, que ante embotellamientos en el área de pintura —el subproceso más recientemente modernizado por la empresa - la firma comenzó a considerar la posibilidad de eliminar por completo el proceso de pintado de los gabinetes de los refrigeradores que fabrica y reemplazarlo por una tecnología de fabricación basada en la adquisición de chapa ya pintada, que es la opción más moderna en la materia. Llama la atención que casi dos décadas después de la apertura económica y la liberalización comercial la empresa esté todavía relativamente lejos del estado del arte internacional.

Este hecho nos lleva a dudar de ideas simplistas que asocian apertura y desregulación económica con cierre de plantas ineficientes, con inversiones en nuevas instalaciones fabriles y con un rápido acercamiento al nivel tecnológico internacional. Estas transiciones parecen llevar mucho más tiempo que lo que se supone en los análisis económicos convencionales.

El cuadro 2 intenta resumir este complejo conjunto de relaciones recíprocas entre lo macroeconómico y lo microeconómico. En las dos columnas iniciales muestra las tres etapas en que con fines analíticos, se puede dividir la historia económica chilena de las últimas décadas, y refleja los cambios en el régimen de incentivos y en el marco regulatorio que en cada una de dichas etapas hubo de introducir la autoridad gubernamental. Estas medidas indujeron cambios en las estrategias empresariales, cuya naturaleza se examina en las otras tres columnas.

Hasta aquí se ha hecho uso del análisis de estática comparativa para comprender el comportamiento de la firma. Sin embargo, resulta claro que este instrumental teórico no basta si se pretende comprender mejor la dinámica evolutiva de la empresa. Se hace necesaria entonces otra metodología que nos permita describir con mayor fineza cómo fue evolucionando la capacidad tecnológica de esta empresa.

La capacidad tecnológica de una firma aparece como un concepto abstracto y difícil de definir, pero 
CUADRO 2

Cambios en las políticas macroeconómicas y en el comportamiento de la industria y de la Compañía Tecno Industrial S.A. (CTI)

\begin{tabular}{|c|c|c|}
\hline \multicolumn{2}{|c|}{ En el país } & En la industria \\
\hline Políticas & Reformas & Estrategias \\
\hline Años 1974-1981 & & \\
\hline $\begin{array}{l}\text { 1974-1978 Control del } \\
\text { gasto del gobierno } \\
\text { Unificación cambiaria } \\
\text { Política monetaria activa } \\
\text { 1979-1981 Tipo de } \\
\text { cambio fijo } \\
\text { Política monetaria pasiva }\end{array}$ & $\begin{array}{l}\text { Liberalización de los } \\
\text { mercados de bienes y de } \\
\text { capitales } \\
\text { Reforma tributaria, } \\
\text { administrativa, de las } \\
\text { empresas públicas, } \\
\text { laboral y previsional }\end{array}$ & $\begin{array}{l}\text { Racionalización } \\
\text { Reestructuración } \\
\text { Mejora de calidad } \\
\text { Cambio en la posición } \\
\text { financiera } \\
\text { Mayor importancia de } \\
\text { exportaciones e } \\
\text { importaciones }\end{array}$ \\
\hline
\end{tabular}

Producto $\quad \frac{\text { En la CTI }}{\text { Organización y proceso }}$

Años 1982-1986

Abandono del tipo de cambio fijo,

desindexación salarial

Políticas para activar la economía

Políticas para reducir el

gasto fiscal

Ajuste fino
Reforma tributaria

Cierre de la economía

Intervención de los

precios (agrícolas)

Nuevas privatizaciones

Intervención de los

bancos
Orientación al exterior
Creación de nuevos
productos
Reducción de costos en
los procesos y la
organización
Reducción de la gama de productos

Compra de licencias

Proyecto de disminución

de costos
Desintegración vertical y fusión para enfrentar cambios

Cambios en el proceso Reorganización para enfrentar el crecimiento Cambio de dueños Inicio de proyectos de inversión

\author{
Fin de las importaciones \\ Búsqueda de menores \\ costos \\ Creación de productos y \\ mejora \\ en la calidad y en los \\ procesos \\ Fin de las inversiones \\ Exportación \\ Desestructuración de la \\ nueva organización \\ Búsqueda de menores \\ costos \\ Reducción de la mano \\ de obra \\ Internalización de \\ procesos con uso \\ intensivo de mano de \\ obra \\ Producción en lotes
}

Años 1987-1994

Aumento y luego control de la masa monetaria Reducción y luego alza del IVA

Manejo de la tasa de interés
Nueva apertura Nueva ley del Banco Central, de CORFO, y cambios en la ley laboral Reforma tributaria Canasta de monedas Mayor liberalización del mercado de capitales
Nuevas inversiones Flexibilización de la estructura organizaciona Diferenciación de productos, mejora de la calidad

Aumento de la productividad de los factores
Reducción de la gama de Reorganización productos

Fin de las exportaciones Sistema CAD

estructural
Creación de planta nueva Reducción de la mano de obra

Compras de máquinas (en lotes) Intento de producir en línea como dice Lundvall (1994), envuelve la habilidad para saber qué hacer, cómo hacerlo, cuándo hacerlo, con quién hacerlo, en cada momento a lo largo del tiempo. Además, supone el desarrollo de conocimientos tecnológicos cada vez mayores en diseño de productos, ingeniería de procesos, tecnologías de organización y métodos de producción.

Con el fin de avanzar en esta dirección supondremos que toda firma opera intentando introducir mejoras en sus rutinas operativas. Para ello identifica los puntos débiles de su operación cotidiana y diseña medidas correctivas que le permiten resolver esos bloqueos. Para hacerlo introduce tanto nuevos equipos como cambios de organización y métodos de trabajo. La empresa puede contar con departamentos técnicos propios encargados de mejorar el diseño de productos, los métodos de trabajo u otros aspectos, o bien puede — a falta de departamentos formales - localizar dicha función fuera de la empresa, adquiriendo servicios a terceros. En la actualidad la CTI subcontrata externamente servicios de ingeniería de diseño de producto, por ejemplo.

Sobre este proceso acumulativo de desarrollo de la capacidad tecnológica de la empresa influyen tanto señales internas como externas a la firma. La percepción de que algo se podría hacer mejor, la visión de los objetivos de largo plazo que trasmiten los propietarios y directores de la firma, aparecen entre los factores internos que condicionan la búsqueda de nuevos conocimientos tecnológicos. Los factores externos, por su lado, derivan de la interacción de la firma con el medio que la rodea, representado entre otros por proveedores, clientes y ferias comerciales.

Importa no sólo el aprender haciendo, que describiera K. Arrow en 1962, sino también el aprender interactuando, recientemente descrito por B. Lundvall. 
Al respecto es crucial la capacidad de la firma para decodificar la información proveniente de revistas técnicas, congresos y ferias internacionales.

Para caracterizar el comportamiento innovativo de la CTI hablaremos aquí de los factores que facilitan o que bloquean estos procesos de aprendizaje.

\section{Hacia una caracterización neoschumpeteriana del proceso innovativo de la CTI}

a) Agentes o factores que inducen cambios en la rutina operativa de esta empresa

Los cambios en los gustos de los consumidores, la aparición de productos sustitutivos con mejores prestaciones que los propios, los cambios en las "visiones" y estrategias de largo plazo de los propietarios de la firma, así como también las modificaciones en los incentivos macroeconómicos a los que ésta debe someterse, son la fuente más clara de señales que motivan cambios en la conducta tecnológica de esta firma. Estos cambios se expresan a través de actividades internas de la firma encaminadas a modificar su rutina operativa, o a través de sus vínculos con proveedores, licenciatarios, vendedores de máquinas y otras personas con las que trabaja. En cada uno de estos vínculos es posible identificar procesos de interacción que implican diversas formas de aprendizaje y de acumulación de experiencia.

En términos generales, la firma no suscribe contratos de largo plazo con sus proveedores de materia prima. Sin embargo, éstos parecen poder programar con tiempo sus entregas dada la estabilidad de la CTI en sus compras. La firma, por lo tanto, ha podido aumentar sus exigencias en términos de calidad y plazos de entrega, mejorando su propio índice de eficiencia interna. La relación de intercambio tecnológico de la CTI con sus proveedores ha estado muy influida por el tamaño y la capacidad técnica de estos últimos. El flujo bilateral de conocimientos ha sido mayor con los proveedores grandes. En cambio a los más pequeños se les ha dado información e incluso algunas veces equipos, pero no parece haber habido retroalimentación tecnológica desde ellos.

Otra forma de incorporar conocimientos y tecnología es a través de la compra de máquinas. En los últimos años, el objetivo primordial de la firma ha sido el de ampliar su capacidad de producción. Las nuevas máquinas que ha adquirido están a la altura de las más avanzadas en el ámbito internacional. Estas máquinas no sólo significan nuevos equipos en la línea de producción, sino que obligan a generar nuevos conocimientos técnicos sobre organización y métodos de tra- bajo para facilitar su integración a las instalaciones físicas de la planta. Esta incorporación lleva a replantearse constantemente el modelo de organización del trabajo y el proceso productivo.

Las relaciones que se han establecido con proveedores de insumos permiten obtener mayor información sobre el tipo de máquinas requeridas por la firma y a la vez mejorar la eficiencia en la compra de insumos. Además, las máquinas se adquieren en países que están en la frontera tecnológica internacional. El $70 \%$ de los insumos es importado, lo que reafirma la gran importancia que para la CTI tiene el vínculo con sus proveedores internacionales de insumos y máquinas.

En cuanto a los distribuidores, la CTI no ha intentado desarrollar una red propia de comercialización; ha dejado la tarea de generar conocimientos en este campo a las empresas distribuidoras y a grandes cadenas de comercialización, como Falabella, Almacenes París y otras. Si éstas buscan obtener descuentos y condiciones preferenciales de compra en función del tamaño de sus pedidos, se define una relación de negociación no exenta de tensiones. No es mucha la retroalimentación técnica que se logra de estos vínculos con las cadenas distribuidoras.

Existe otro camino para relacionarse directamente con la demanda y captar información tecnológica que permita a la firma orientar la generación de nuevos conocimientos técnicos: es el servicio de posventa, que constituye una fuente importante de información acerca de piezas defectuosas, sistemas operativos que repiten dificultades de funcionamiento, etc. En este plano la firma ha desarrollado una estrategia descentralizada, creando una filial (CST) encargada de capacitar a pequeñas empresas concesionarias para el servicio de los equipos vendidos. La CTI brinda capacitación a estos subcontratistas, buscando bloquear la prestación de servicios de mantenimiento a otras marcas.

Resta por destacar que se observó poca comunicación con otros fabricantes locales de refrigeradores. Al parecer éstos tampoco mantienen contacto entre ellos y no interactúan en cámaras gremiales o empresariales dedicadas a atender intereses comunes al sector. Esto obstaculiza formas cruzadas de transferencia de información técnica que en otros campos de la actividad industrial adquieren cierta importancia.

\section{b) El núcleo humano que introduce cambios en la rutina operativa de la CTI \\ A lo largo de los años setenta y ochenta el orga- nigrama de la CTI no tuvo cambios muy significativos. La creación en 1989 de la Gerencia de Ingeniería y Desarrollo y de la Gerencia de Producción marcó el}


comienzo de una nueva actitud hacia la generación y uso de conocimientos técnicos. Luego, en 1993, estos departamentos se transformaron en la Gerencia de Refrigeradores y Cocinas y la Gerencia de Lavadoras y Estufas, al tiempo que la estrategia de la firma se orientaba más hacia la ingeniería de procesos que hacia el diseño de productos. En 1994 se creó la División de Control de Calidad con el fin de centralizar la generación de bases de datos y el seguimiento de las mejoras técnicas. Las restantes gerencias de la firma - Comercial, de Administración y de Finanzas - son de larga data y han logrado acumular una vasta experiencia en sus respectivos campos de acción.

Uno de los ámbitos con menos desarrollo es el relacionado con la calificación de recursos humanos. Existe una relación verticalista entre operarios de planta e ingenieros y técnicos, con un supervisor que actúa como intermediario. No está desarrollada en la empresa la capacidad de recuperar sugerencias técnicas de abajo hacia arriba, perdiéndose así parte del proceso de retroalimentación y aprendizaje.

Los ingenieros y técnicos son importantes vehículos de desarrollo e introducción de nuevos conocimientos técnicos. Ellos son quienes plasman las nuevas rutinas y desarrollan las mejoras de ingeniería que llevan a abaratar procesos y a elevar la calidad, trabajo que es apoyado por laboratorios. Al estudiar la historia reciente de la empresa se observa que efectivamente en los últimos años ha habido un cambio en la estrategia tecnológica. Los profesionales dedicados a la ingeniería de procesos han aumentado significativamente, conjuntamente con la apertura y puesta en marcha de la nueva planta fabril. En cambio, han perdido terreno los técnicos y profesionales que trabajan en el diseño de productos y la firma ha decidido subcontratar con terceros esta actividad.

\section{c) Losfacilitadores externos del aprendizaje tecno- lógico}

Un importante proveedor de conocimientos técnicos es Aristón, una firma italiana que produce refrigeradores y otros aparatos electrodomésticos. Sin embargo, las diferentes realidades de mercado y capacitación tecnológica de ambos países con frecuencia han obligado a los ingenieros chilenos a desechar parte de la información técnica recibida de la firma italiana. Esto quedó de manifiesto con ocasión del diseño de la nueva planta puesta en marcha en fecha reciente.

Los proveedores de equipos generalmente brindan capacitación conjuntamente con la instalación y pues- ta en marcha de nuevas máquinas. Se da poca capacitación en el trabajo y no parece haber en Chile mecanismos estables para la transferencia de conocimientos técnicos hacia la firma desde institutos tecnológicos o agentes de extensión industrial del sistema público de innovación tecnológica.

En opinión del sector obrero, los trabajadores están preparados para enfrentar los cambios en los diseños de productos y en los procesos de fabricación introducidos, porque los trabajos son relativamente sencillos y las nuevas técnicas no introducen grandes complejidades, en tanto que buena parte de la capacidad tecnológica de la firma se concentra en sus técnicos e ingenieros.

En los últimos años se ha elevado el nivel de exigencias en la contratación de nuevos operarios, básicamente en términos de educación formal. Aunque con esto se ha hecho más difícil conseguir operarios de fábrica adecuados, los beneficios parecen ser mayores por la más alta capacidad de aprender de los nuevos obreros.

Al parecer la empresa ha usado muy poco el sistema público de capacitación (SENCE). Tampoco ha hecho uso del financiamiento asociado a programas del FONTEC, la CORFO u otras agencias del sistema de innovación tecnológica del país.

La CTI no se caracteriza por haber construido un 'sistema' innovativo estable y desarrollado al interior de la empresa ni por haber comprometido un monto significativo de recursos con este fin. Por el carácter verticalista de sus relaciones laborales y su escaso esfuerzo en la capacitación de operarios, hay poca retroalimentación de abajo hacia arriba en lo que a generación y difusión de nuevos conocimientos técnicos se refiere, y la acumulación de capacidades técnicas está fundamentalmente radicada en los profesionales de la empresa. Nunca se llegó realmente a establecer un 'clima' cooperativo con los núcleos operarios de la firma.

En los últimos años la firma ha comenzado a encarar con más vigor su proyecto de internacionalización con vistas a su futura participación en el Mercosur y en dicho contexto comienza a dar mayor importancia al tema tecnológico. Queda claro, al examinar lo ocurrido, que la empresa deberá invertir significativamente tanto en equipos como en formación de recursos humanos si quiere expandirse hacia terceros mercados desde una base interna sólida que le permita mantener el liderazgo tecnológico como grupo económico que se proyecta a la escala internacional. 


\section{V}

\section{Conclusiones}

Lo expuesto en este artículo permite entender el lento proceso de transformación de una empresa metalmecánica chilena y de su adaptación al cambiante régimen de incentivos macroeconómicos que surgió tras la apertura y desregulación de la economía. Se ve cómo la empresa ha logrado sobrevivir en un marco altamente competitivo, no solamente por la existencia de fallas de mercado, sino por su propia capacidad para generar un nicho relativamente protegido por marcas de fábrica, prestigio empresarial y un servicio de posventa adecuado. Entre las firmas surgidas en el período de industrialización protegida por barreras arancelarias, son varias las que desaparecieron durante el proceso de apertura de la economía chilena y que, a diferencia de la en, no lograron superar con éxito los escollos de la adaptación a un nuevo régimen de incentivos macroeconómicos.

Aquí se ha mostrado que el comportamiento de esta firma "dibuja" con bastante precisión el funcionamiento agregado del sector metalmecánico chileno. El análisis ha complementado una visión sistémica de su proceso de aprendizaje tecnológico, con técnicas provenientes de la estática comparativa convencional y de la teoría de los precios.

Asimismo, se ha intentado relacionar lo macroeconómico con lo microeconómico, buscando iluminar las complejas interrelaciones entre ambas esferas del análisis económico. Los resultados de la investigación han señalado que la turbulencia macroeconómica y el nuevo escenario regulatorio e institucional de los años setenta cambió la estrategia de largo plazo de la CTI y su forma de enfrentar los temas del crecimiento.

Se ha corroborado también que la transición a un nuevo patrón de comportamiento tras la apertura y desregulación de la economía es un proceso lento y complejo, que no debe imaginarse como íntegramente terminado aún en la actualidad, casi dos décadas después de haberse iniciado los esfuerzos de reforma estructural.

Hemos visto que aún hoy la CTI es un complejo mosaico de islas de modernidad y zonas de atraso tecnológico, y que sólo en fecha muy reciente ha comenzado a tomar en cuenta las tecnologías más modernas en su campo de operación, a fin de pensar en su estrategia de largo plazo. Todavía no estamos en presencia de una empresa de envergadura internacional, tanto en términos de inversiones físicas como de desarrollo de capacidad tecnológica propia. Es mucho lo que le resta por progresar para alcanzar esa posición.

Los esfuerzos de internacionalización han comenzado en fecha reciente, ante las señales provenientes del Mercosur, y con ellos han aparecido nuevas exigencias tecnológicas y de organización que la firma deberá encarar gradualmente. El desarrollo de la capacidad tecnológica interna y las inversiones físicas en nuevas instalaciones productivas deberán acompañar el proceso hacia una escala operativa muy superior a la alcanzada hasta ahora.

\section{Bibliografía}

Agacino, R., G. Rivas y E. Román (1992): Apertura y eficiencia productiva: la experiencia chilena 1975-1989, Documento de trabajo, $\mathrm{N}^{\circ}$ 92, Santiago de Chile, Programa de Economía del Trabajo (PET)

Castillo, M, C. Maggi y M. Dini (1994): Reorganización industrial y estrategias competitivas en Chile, LC/R.1467, Santiago de Chile, Comisión Económica para América Latina y el Caribe (CEPAL), Unidad Conjunta CEPAL/ONUDI de Desarrollo Industrial y Tecnológico.

Corbo, V. y J.M. Sánchez (1992): El ajuste de las empresas del sector industrial en Chile durante 1974-1982, Colección estudios CIEPLAN $\mathrm{N}^{\circ} 35$, Santiago de Chile, Corporación de Investigaciones Económicas para Latinoamérica (CIEPLAN).

CEPAL/CIID (Comisión Económica para América Latina y el Caribe/ Centro Internacional de Investigaciones para el Desarrollo) (1995): La industria chilena entre 1970-1994: de la sustitución de importaciones a la segunda fase exportadora, LC/R.1535, Santiago de Chile.
INE (Instituto Nacional de Estadísticas) (varios años): Anuario estadístico, Santiago de Chile.

Lundvall, B. (1994): National System of Innovation: Towards a Theory of Innovation and Interactive Learning, Londres, Printer.

Marshall, I. (1992): Liberalización comercial en Chile y su impacto sobre la eficiencia técnica industrial:1974-1986, Colección estudios CIEPLAN, $\mathrm{N}^{\circ} 35$, Santiago de Chile, CIEPLAN.

Mizala, A. (1992): Las reformas económicas de los años setenta y la industria manufacturera chilena, Colección estudios CIEPLAN, $\mathrm{N}^{\circ}$ 35, Santiago de Chile, CIEPLAN.

Meller, P. (1992): La apertura comercial chilena: lecciones de política, Colección estudios CIEPLAN, №35, Santiago de Chile, CIEPLAN.

Rosenberg, N. (1976): Perspectives on Technology, Cambridge, Reino Unido, Cambridge University Press. 